
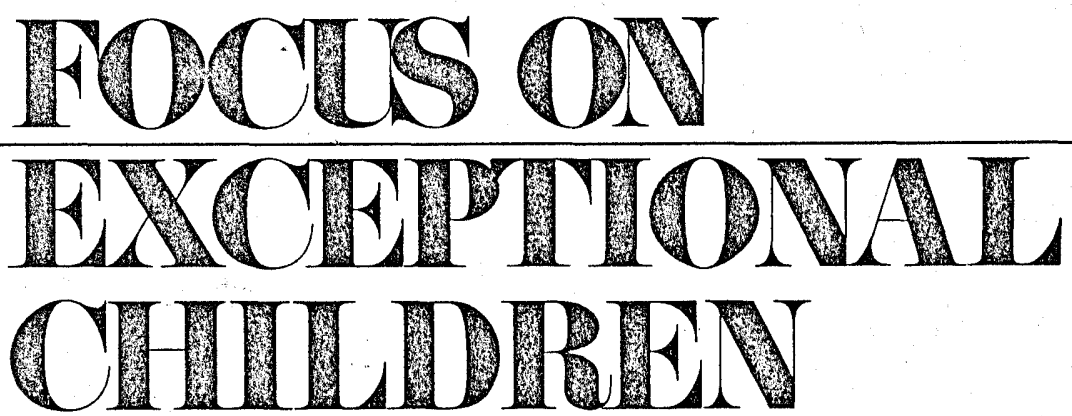

EDUCATIONALLY HANDICAPPED AND THE ENGINEERED CLASSROOM

\section{AN EDUCATIONAL SOLUTION}

\section{Robert J. Stillwell, Alfred A. Artuso, Frank M. Hewett, and Frank D. Taylor ${ }^{1}$}

Public school educators today have a growing concern about the ever-increasing number of inattentive, failure-prone, hyperactive children who cannot be contained within the usual classroom structure. Often all appropriate public school techniques have been exhausted and both teachers and administrators have been unable to find a suitable solution.

It is apparent that many of these students have the potential to achieve in school if some appropriate program could be developed for them. It has not been enough merely to label them as school failures or potential dropouts. Repeated student and parent conferences, transfers to other classrooms or schools, intervention from outside agencies, suspension, expulsion, and home instruction have all been utilized, with little or no noticeable effect. At the same time it has not always been feasible to leave the disordered student in the regular classroom.

In an effort to find more appropriate solutions, education looked to the disciplines of medicine, psychiatry, and neurology for help. Such phrases as "neurologically impaired," "brain damaged," "perceptually handicapped," "school phobic," "neurotic," and "emotionally disturbed" were soon added to the vocabulary of many teachers, administrators, and parents. Often the only contribution this terminology made was to glamorize a diagnosis that was not always functional for the classroom teacher attempting to cope with problem students on a day-to-day basis.

What was needed was an instructional program that would be meaningful to a teacher, translatable to a classroom, and have promise of changing the behavior of the increasing number of students described earlier and often labeled educationally handicapped or emotionally disturbed.

Dr. Frank M. Hewett, Head of the Neuro-Psychiatric Institute School at U.C.L.A. envisioned a possible educational solution for the problem. He hypothesized that what was needed was basically an educational model-a development sequencethat would provide for the merging of sound individualized instructional techniques. already in use in many classrooms with some aspects of behavior modification theory.

1. Robert J. Stillwell is Coordinator of Educationally Handicapped and Alfred A. Artuso is Superintendent of the Santa Monica Unified School District. Frank M. Hewett is Associate Professor of Education and Psychiatry and Chairman, Area of Special Education, University of California, Los Angeles. Frank D. Taylor is Director of Special Services for the Santa Monica Unified School District. 
Dr. Alfred A. Artuso, Superintendent, and Dr. Frank D. Taylor, Director of Special Services, of the Santa Monica Unified School District cooperated with Dr. Hewett in evaluating this new model, now known as the Engineered Classroom.

This cooperative endeavor between a public school system and a major university has proven very productive. The University provides the creative talents of experts in learning theory and the knowledge for sound research studies. The public schools are a resource for personnel in developing classroom procedures and curriculum while providing the opportunity of testing an educational innovation in the reality of the "real world." In the final analysis the value of any educational innovation must not be decided until after it has stood the test of a genuine public school situation.

Over the past four years, in a project partially funded by two Tittle III Demonstration Grants, there have been as many as twelve classrooms in operation, from primary through junior high school grades. These classes are in schools in a typical urban community with all the concerns of public school teachers, administrators, P.T.A. organizations, and parents, while still encompassing the full spectrum of ethnic and socio-economic backgrounds ideally structured for research.

The classrooms for educationally handicapped students as developed in Santa Monica provide the teacher with a carefully structured plan for assigning appropriate educational tasks to students, providing meaningful rewards for learning, and for maintaining student-like behavior within well-defined limits. Specific instructional materials already utilized by many school systems in individualizing instruction, the concept of the developmental sequence of educational goals (Hewett, 1968), and a

FOCUS ON EXCEPTIONAL CHILDREN is published monthly except June, July, and August as a service to those concerned with mentally retarded and emotionally disturbed children. Subscriptions rates, $\$ 9.50$ per year. Copyright 1970 Love Publishing Company. All rights reserved. Reproduction in whole or part without written permission is prohibited. Printed in the United States of America. Second class postage is paid at Denver, Colorado.

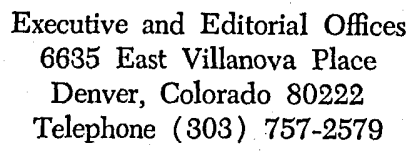

\section{EDITOR}

Dr. Edward L. Meyen

The University of Iowa

Washington Report

Valeita J. Naegle
Stanley F. Love Publisher pragmatic use of some aspects of behavior modification provide the foundation of the basic elements of the educational solution.

The first element of the educational solution is the developmental sequence.

\section{A Developmental Sequence of Educational Goals}

The developmental sequence mentioned earlier postulates six educational task levels. These goals or behavioral categories move from attention, response, order, exploratory, and social to mastery. (See Figure I) The implication is that we must gain a child's attention and make contact with him, get him to participate and respond in learning, aid him in adapting to routines and direction following, help him to accurately and thoroughly explore his environment through multi-sensory experience, learn to gain the approval of others and avoid their disapproval, and finally master academic skills of reading and arithmetic and gain knowledge in curriculum content areas.

The child is taken where he is on this developmental sequence, his weaknesses bolstered and his strengths supported. While the ultimate goal of the teacher is to engage the student at the mastery level, children must first be considered in terms of their development at lower levels, and assignments in school must take this into account. In helping an educationally handicapped child get ready for intellectual training the teacher can profitably use the behavior modification principle of shaping rather than hold out for the ultimate goal.

The second element of the structure is the classroom setting.

\section{Classroom Setting}

The typical elementary classroom is $20^{\prime}$ by $30^{\prime}$, well lighted, portable classroom, with double desks $\left(2^{\prime} \times 4^{\prime}\right)$ for each of the 9 to 12 pupils. The physical environment can be described according to four major centers, paralleling levels on the developmental sequence of educational goals. The Mastery Center consists of the student desk area where academic assignments are undertaken, and study booths or "offices" where the student continues his academic progress is another postural setting. An Exploratory Center is set up near the windows, and there are sink facilities for simple science experiments, arts, and crafts. A Communication Center where social skills are fostered is also located in the back of the room. The Order Center consists of tables where games, puzzles, exercises, and activities emphasizing attention, orderly response, and routine are kept. (Figure II) 
FIGURE ?

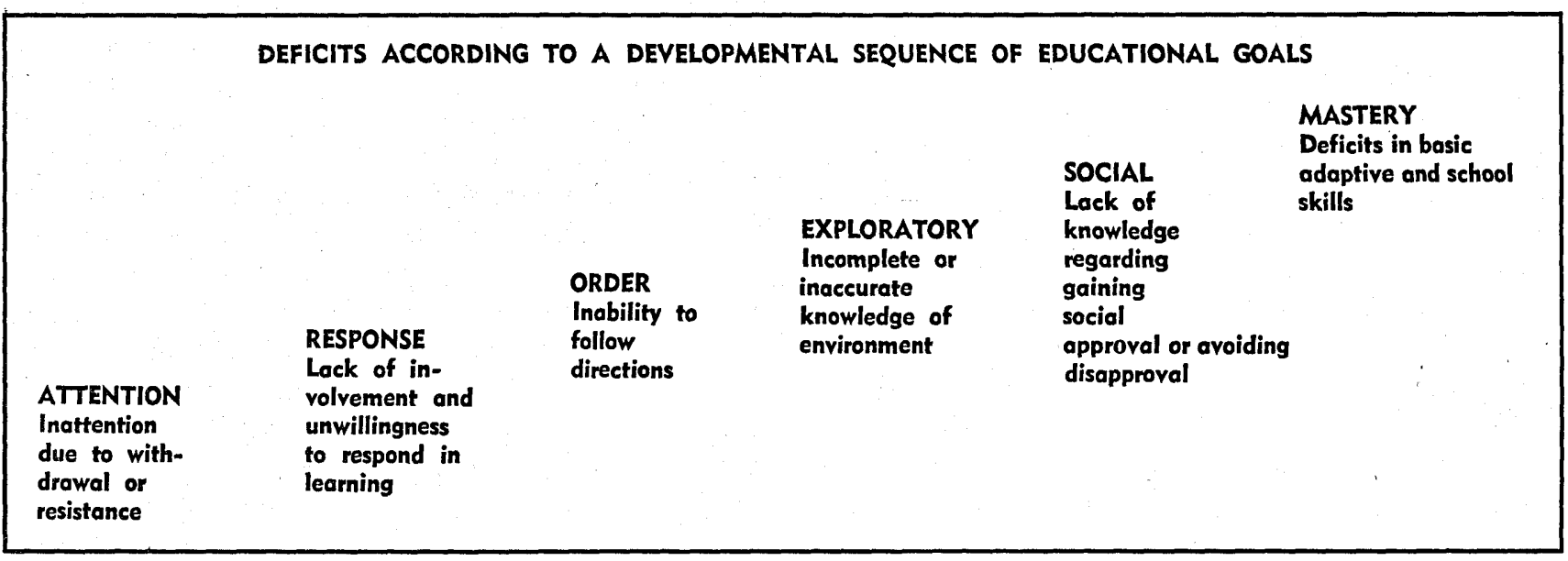

FIGURE II

ELEMENTARY SCHOOL CLASSROOM

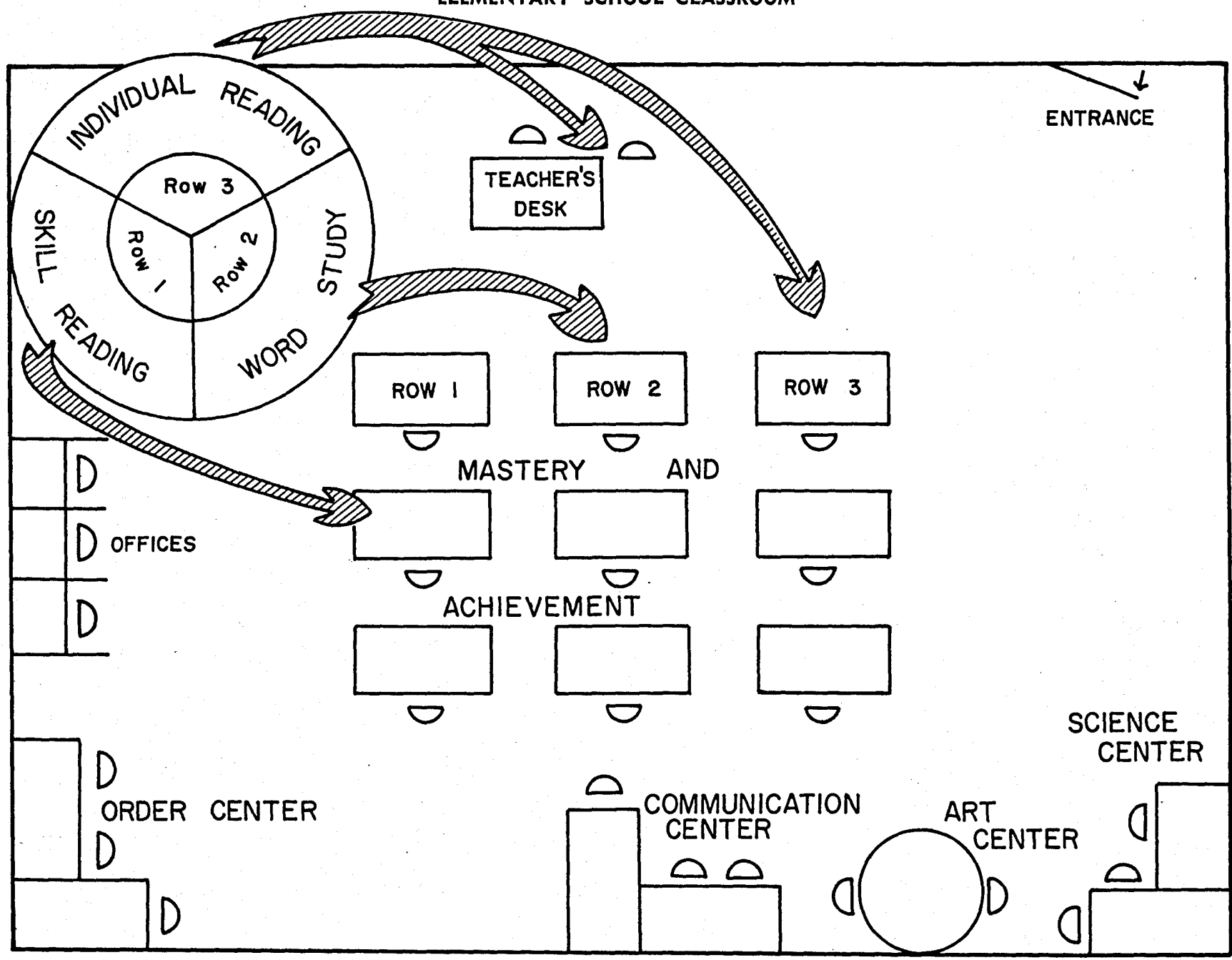


While the classrooms at the junior high school level are the same size and the same four centers are present, the room was designed to provide greater flexibility. The student "home base" in the room has armchair desks (Station One) exactly like those used in other classrooms in the school. Around this area are three additional work areas. Station Two has three study carrels, with soft upholstered chairs and reference materials such as a dictionary, telephone book, department store catalog and an almanac placed in each one. Station Three features three drafting tables with high stools to offer a marked shift in sitting and working position, as well as setting. Station Four has three large tables offering still another setting. The rationale for setting up these four stations within the Mastery Area is that frequent moving to a dif- ferent setting or working position appears to facilitate interest and concentration with this action-oriented adolescent group. During the day the teacher may rotate the entire class or only selected members through these work stations. The exploratory center (Station Five) stresses appropriate junior high science content and may have a stand-up work counter for another setting. The art center (Station Six) and communication center (Station Seven) utilize many of the same types of tasks found effective with elementary age children and the order center (Station Eight) often contains mechanical parts such as a simple one-cylinder engine which can be dismantled piece by piece and reassembled. Puzzles and other direction-following activities are also found here. (Figure III)

FIGURE III

JUNIOR HIGH SCHOOL CLASSROOM

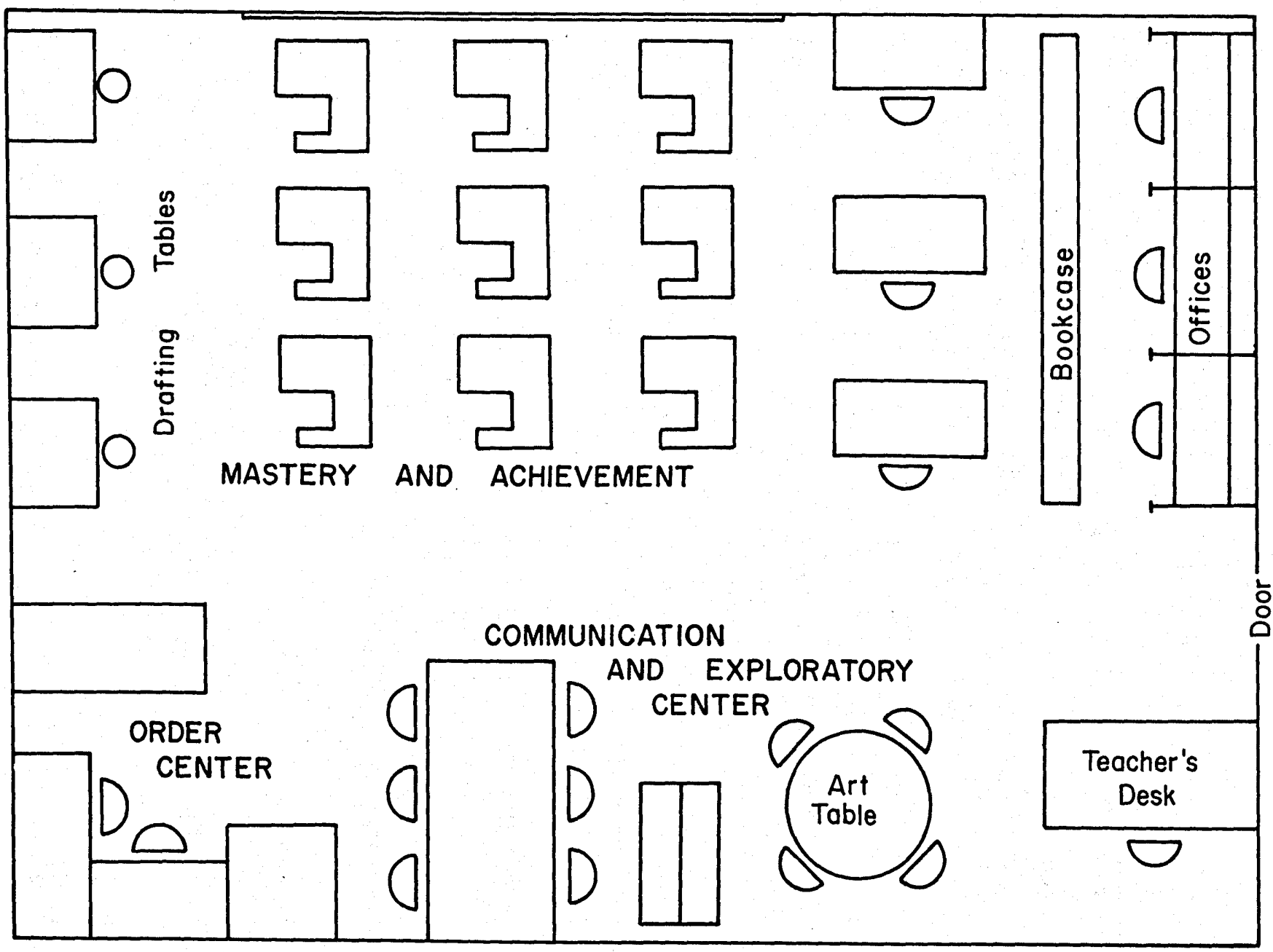


The classrooms are under the supervision of a regular teacher and a teacher aide. The aide need not be a credentialed or specifically trained individual. High school graduates and PTA volunteers have been employed.

The third element of the structure is the concept of the Work Record Card or the Check Mark System.

\section{The Check Mark System}

Mounted by the door is a Work Record Card Holder, much like a time card rack near the time clock in a factory. An individual Work Record Card for each student is in the holder. As each student enters the room in the morning he picks up his individual Work Record Card which is ruled with approximately 190 squares. As the student moves through the day the teacher and aide recognize his efficiency to function as a student by giving check marks on the Work Record Card. The student carries his Card with him wherever he goes in the room. Check marks are given on a fixed interval basis with a possible 10 check marks for each 15 minutes. (Figure IV)

\section{FIGURE IV}

\section{WORK RECORD CARD AND CHECK MARK SYSTEM}

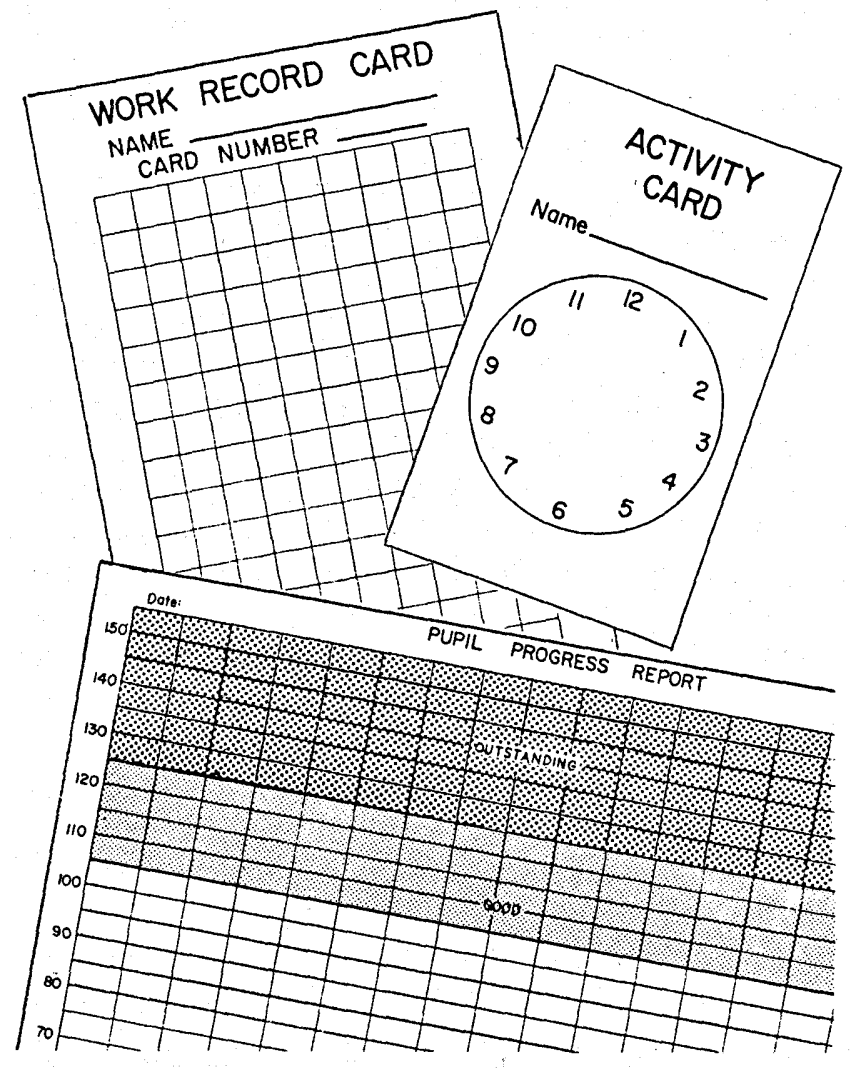

This system attempts to provide rewards on a concrete, immediate basis for children who have not been responsive to the more typical kinds of rewards provided by school (e.g., long-range grades, praise, parental recognition, competition, etc.). The teacher attempts to convey the idea that check marks are objective measures of accomplishment and literally part of a reality system in the classroom, over which the teacher has little subjective control. Student save completed Work Record Cards that can be exchanged for one of the exchange items available in Phases I, II, and III.

During Phase I students may exchange a completed Work Record Card for a simple trinket or a candy reward. Phases II and III provide opportunities to exchange the Work Record Cards for 15 minutes of free choice activity time at one of the Centers within the room or a report card-complimentary note home to parents. As students approach reintegration into regular classrooms they move from the more basic candy or trinket rewards of Phase I to the more typical school type reporting forms of Phase III.

The fourth element of the structure is the use of interventions.

\section{Classroom Interventions}

Earlier it was suggested that one of the essential ingredients in all learning situations was a suitable educational task-a task that made it possible for each individual student to succeed at all times. Thus, the teacher must be aware of each student's progress throughout the school day and be ready to intervene at any time when a given task assignment proves inappropriate. Nine specific interventions have been developed which encompass the six levels on the developmental sequence of educational goals.

As long as the child is able to stabilize himself during any of the student interventions, he continues to earn check marks on a par with those students successfully pursuing mastery level assignments. $\mathrm{He}$ is in no way penalized for the shift in assignment made by the teacher.

If, at any time during the school day, a student begins to display signs of maladaptive learning behavior (e.g., inattention, day dreaming, boredom, disruption) the teacher has appropriate resources in the form of interventions to meet the situation.

Figure V summarizes the interventions which may be utilized in an attempt to foster adaptive student functioning. The teacher may select any intervention seen as appropriate with a given student or may try the student at each intervention level until his behavior improves. 
Actual practice has shown that it is only on rare occasions that the teacher needs to employ a time-out or exclusion.

\section{FIGURE $V$}

Hierarchy of Interventions to Maintain Student Role

Level Student Interventions

1. Mastery

a. Assign student to study booth to pursue mastery work.

b. Modify mastery assignment and have student continue at desk or in study booth.

2. Social

Verbally restructure expectation of student role (e.g., respect working rights of others, accept limits of time, space, activity).

3. Exploratory

Remove mastery assignment and reassign to Exploratory Center for specific science, art, or communication activity.

4. Order

Reassign to Order Center for specific direction following tasks (e.g., puzzle, exercise, game, work sheet).

Remove child from classroom and assign him to a task he likes to do and can do success-

5. Response fully outside (e.g., running around playground, punching punching bag, furning specific number of somersaults on (awn).

Remove child from classroom, put on a oneto-one tutoring relationship with teacher aide, and increase use of extrinsic motivators to obtain cooperation, attention, and student behavior.

\section{Non-student Interventions}

Take away work record card and explain to

7. Time Out child he cannot earn checkmarks for a specific number of minutes which he must spend in isolation in room adjacent to class.

If the child is not able to function in time8. Exclusion out room, immediately suspend him from class and, if possible, send him home.

The fifth element of the structure is the daily instructional program.

\section{Daily Instructional Program}

The original daily schedule and curriculum of the Engineered Classroom has been constantly assessed and modified, not only in Santa Monica but in other school districts throughout the country. It should be obvious that although the following program suggests specific activities the students, facilities, community needs, and individual school may dictate considerable changes in time blocks and subject matter. (Figure VI)

An attempt has been made to provide the classroom teacher with specific ideas that minimize the preparation of endless ditto masters, while maximizing the individu-
FIGURE VI

DAILY SCHEDULE

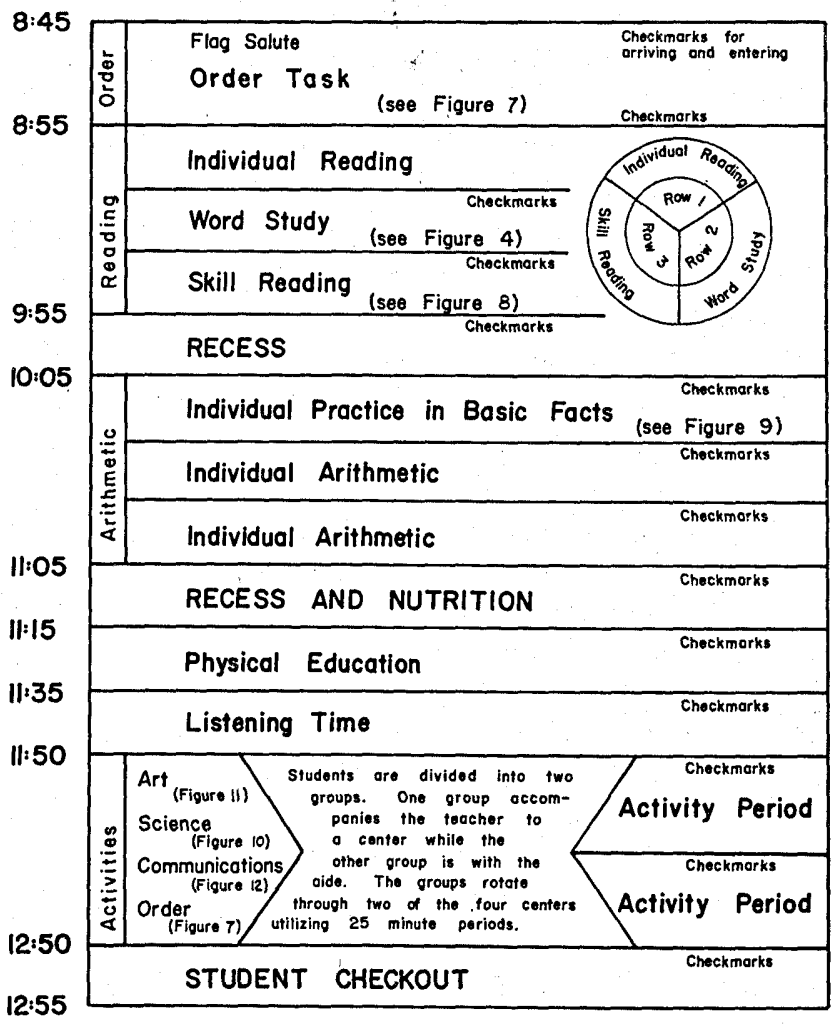

alization of instruction for each of the students. This is accomplished, in part, by utilizing commercially available self-correcting materials such as S.R.A. Reading Labs, Sullivan Programmed Arithmetic and Reading Materials, Write and See Phonics and Reader's Digest Materials, and by capitalizing on the teacher and teacher aides themselves as "instructional material." For example, during two of the three time blocks in both Reading and Arithmetic, the teacher and aide rely primarily on individual or small group instruction at the teacher's desk, the pupil's desk, or the chalkboard. Instruction at this time is largely personalized through participation on the part of the pupil with a library book, arithmetic at the chalkboard, or an immediate follow-up task assigned by the teacher or aide. Typical workbook ditto-type lessons are not utilized since the teacher becomes the "textbook."

At times during the day when worksheets are needed the teacher uses either commercially available materials or open-ended multilevel assignments developed by staff members of the Santa Monica Schools.

The initial assignment of the day, given during the order period, is designed to provide the students with a simple paper and pencil or a concrete manipulative di- 
rection-following task that can be easily completed in a successful manner. Commercially available perceptual motor training work sheets are used along with other nonverbal tracing, design copying, or visual discrimination tasks. (Figure VII)
The reading program is divided into three 15 -minute periods. Individual reading is done at the teacher's desk with each child. The child brings his work reader (a basal or remedial text close to his actual functioning level) to the desk and reads aloud with the teacher aide

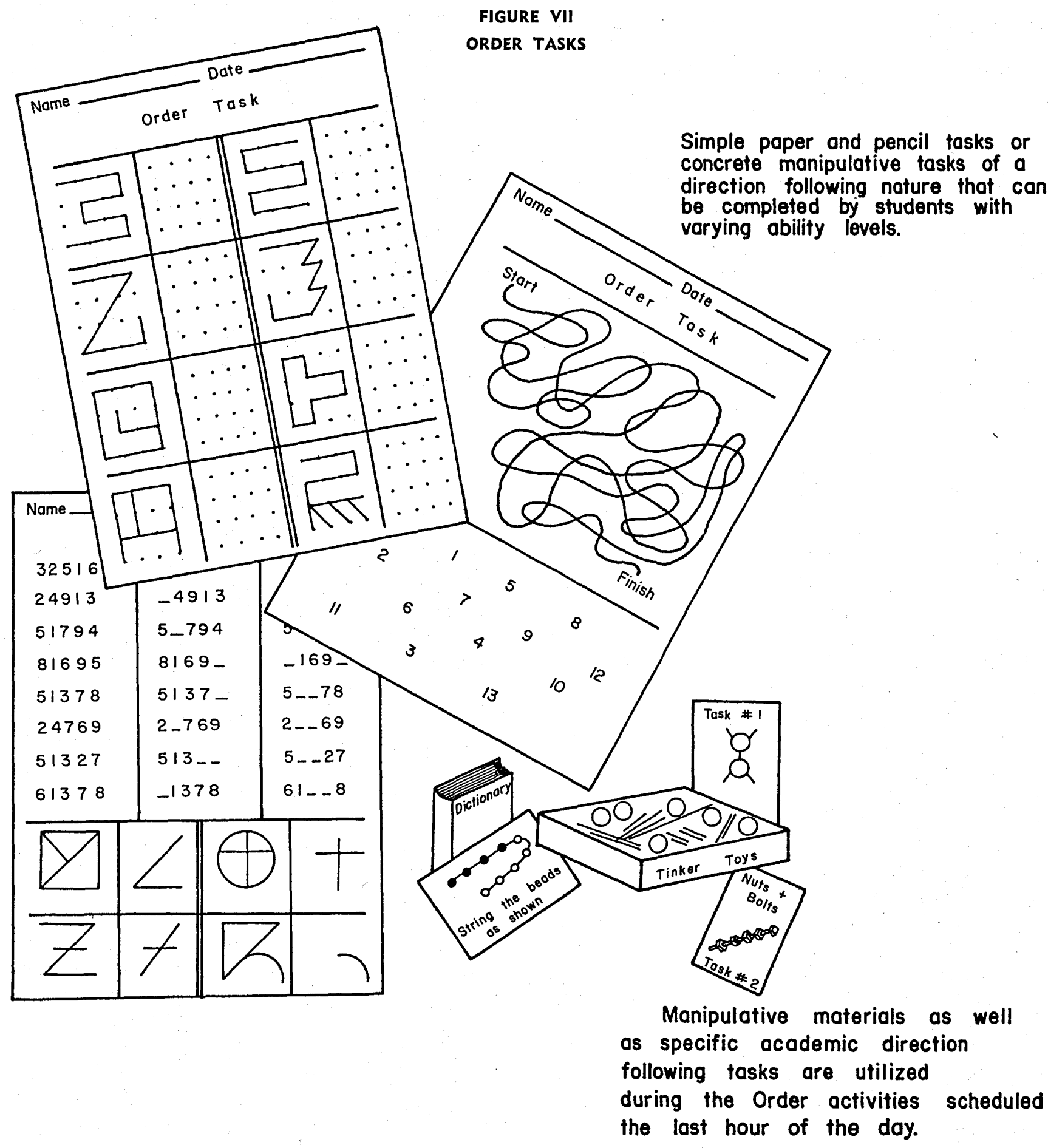


for a three-minute period. The three minutes are timed by a small hourglass which the child turns over when he is ready to start reading. As the child correctly completes each line of reading material the teacher aide dispenses an appropriate reward to the student. The aide also keeps a record of each word the child misreads, and these are printed on a $3^{\prime \prime} \times 5^{\prime \prime}$ file card for later study. At the end of the 3-minute period the teacher aide and child work on tasks that help develop comprehension and then the child takes his reward and the new reading words back to his desk. Candy is used initially in this activity because of the high motivation it produces, exhibited by students when practicing their reading before going to the teacher aide's desk and their concentration during oral reading.

While the initial reward may have been candy ( $M$ \& M's), the students are soon working for check marks that can be exchanged for activity time, or plastic counters dropped into a cup and later counted and graphed.

After each child in a given group has had individual reading, an assignment wheel is turned; the teacher has all students put down their work and both teacher and aide circulate, giving children their check marks. This takes approximately three to five minutes, during which time the children also learn to wait quietly. The bonus check marks given for "being a student" will reflect such "waiting" behavior.

Next, the groups move to either word study or skill reading. Word study is done at the child's desk. The teacher circulates (while the aide continues individual reading with another group of three students) and works with individual students or small groups on reading skills. Spelling words acquired during story writing (discussed later) are also reviewed as spelling words at this time.

Following word study, the wheel is turned and check marks are given all students. It is important to point out that during the check mark-giving period, not only is the previous assignment corrected and acknowledged with check marks, but the next assignment is introduced. It has been found that this type of individual transition period is very useful in maintaining the work-oriented atmosphere in the class. The teacher does not rely on verbal assignments in front of the class by repeatedly calling out, "Boys and girls! Boys and girls! That means you too, Henry! Give me your attention! I am waiting for two people in row three." etc.

Skill reading involves an independent vocabulary and comprehension building activity, and commercial materials, including programmed or individualized ones such as Sullivan Programmed Readers, S.R.A., Write and See, or Barnell Loft materials are used. The Santa Monica staff has also developed some open-ended-multilevel word games and decoding exercises that can be used occasionally during this time. (Figure VIII)

The interventions used to assist a child who is having difficulty with a reading assignment or any other assignment for a period of time utilize the centers around the room. Students may be assigned to do a simple puzzle at the Order Center, listen to the record player at the Communications Area, or complete an art or science task at one of the other centers.

Twice a week, Story Writing is done by the entire class rather than in small groups. The teacher usually makes a short motivation presentation in some area of interest to the class (e.g., knighthood, deep sea life) and the students are encouraged to write about the topic.

Following either reading or story writing, the class is dismissed for recess. This is taken outside the room, and as each child leaves he puts his Work Record Card away in its holder. Upon returning the card is picked up and the children receive up to a possible ten check marks for the recess period.

The arithmetic period occupies the next hour, which is divided into three periods of about 15 minutes each. The students are also divided into three groups based somewhat on their ability. One of the groups is working on arithmetic fundamentals, including basic addition, subtraction, division and multiplication. The Santa Monica staff has adopted and developed multi-level arithmetic drill sheets (Figure IX) which can be quickly modified to fit a particular student's individual instructional needs. A second group of three to four students is working at the chalkboard or around a larger table at one of the centers with the teacher or teacher aide, learning new skills or getting help in problem-solving techniques. The third group may be using pages taken from a workbook, the SRA Computational Skills Kit, Junior Scholastic Materials, or solving problems put on the chalkboard by the teacher. Approximately every 15 minutes all work stops -assignments are corrected, checkmarks given, and students rotate to the next assignment.

During the next 20 to 25 minute period the students leave the classroom for physical education. Generally the teachers use low organized games that do not emphasize competitive skills but do have a lead-up value for games typically engaged in by their peers in regular classes. Work Record Cards are taken outside to the playground and checks are given when students reach the play area, finish their play, and return to the room. 
FIGURE VIII

SKILL READING TASKS

Multi-level tasks differ from regular worksheets because teachers can easily

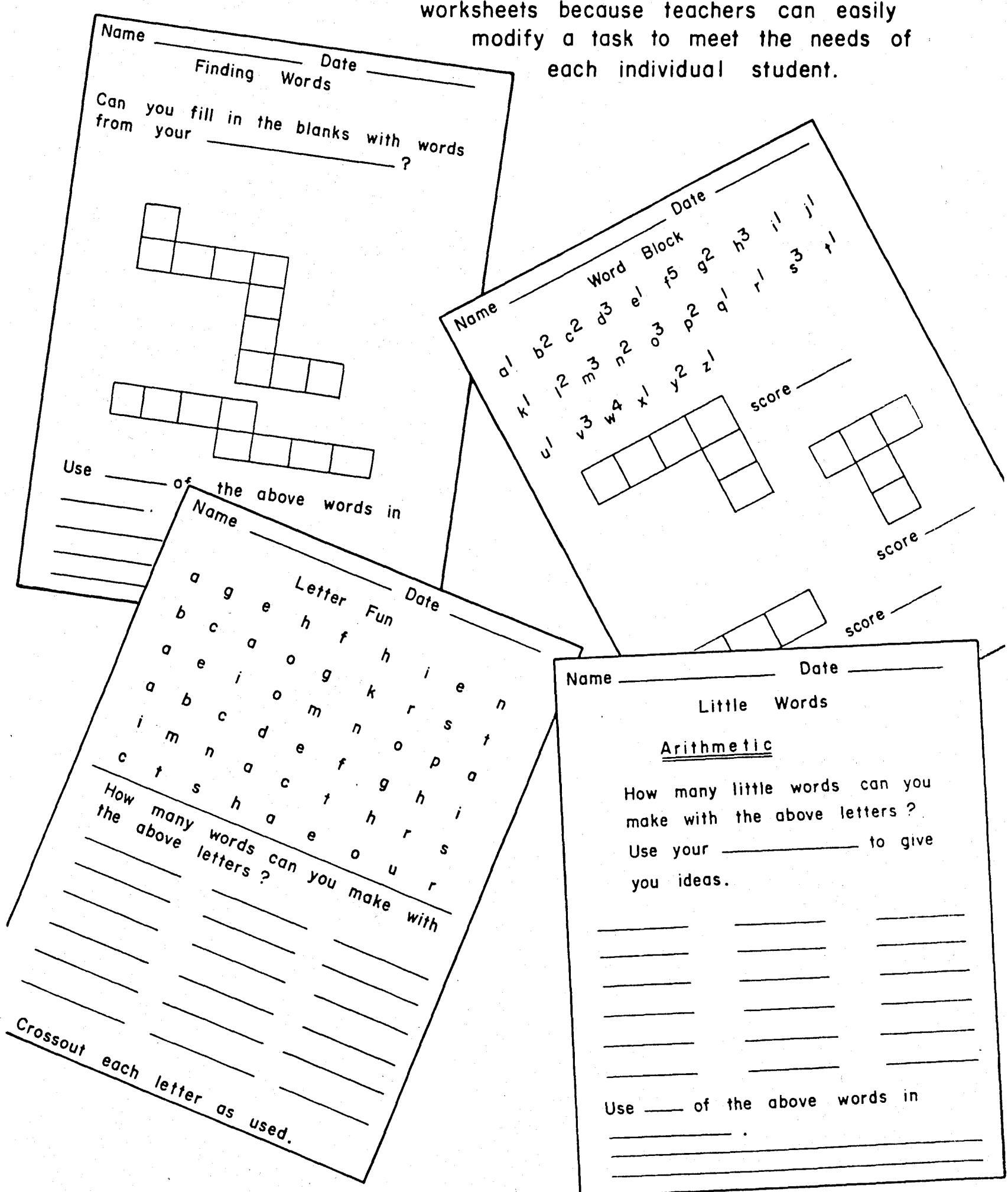


Following the lunch period a 10 to 15 minute group listening activity may be used to help students effect a transition from the active play on the playground to the more restricted behavior in the classroom. During this time the teacher reads a portion of a continuing story aloud.

The next period of the day is devoted to exploratory activities. The class is divided in half with one group going to a center with the teacher while the other group goes to a center with the aide. Students spend from 20 to 25 minutes working at the centers in the back of the room. At the end of this period the two groups either exchange centers or rotate to another center.

Each task is selected for its intriguing interest value

FIGURE IX

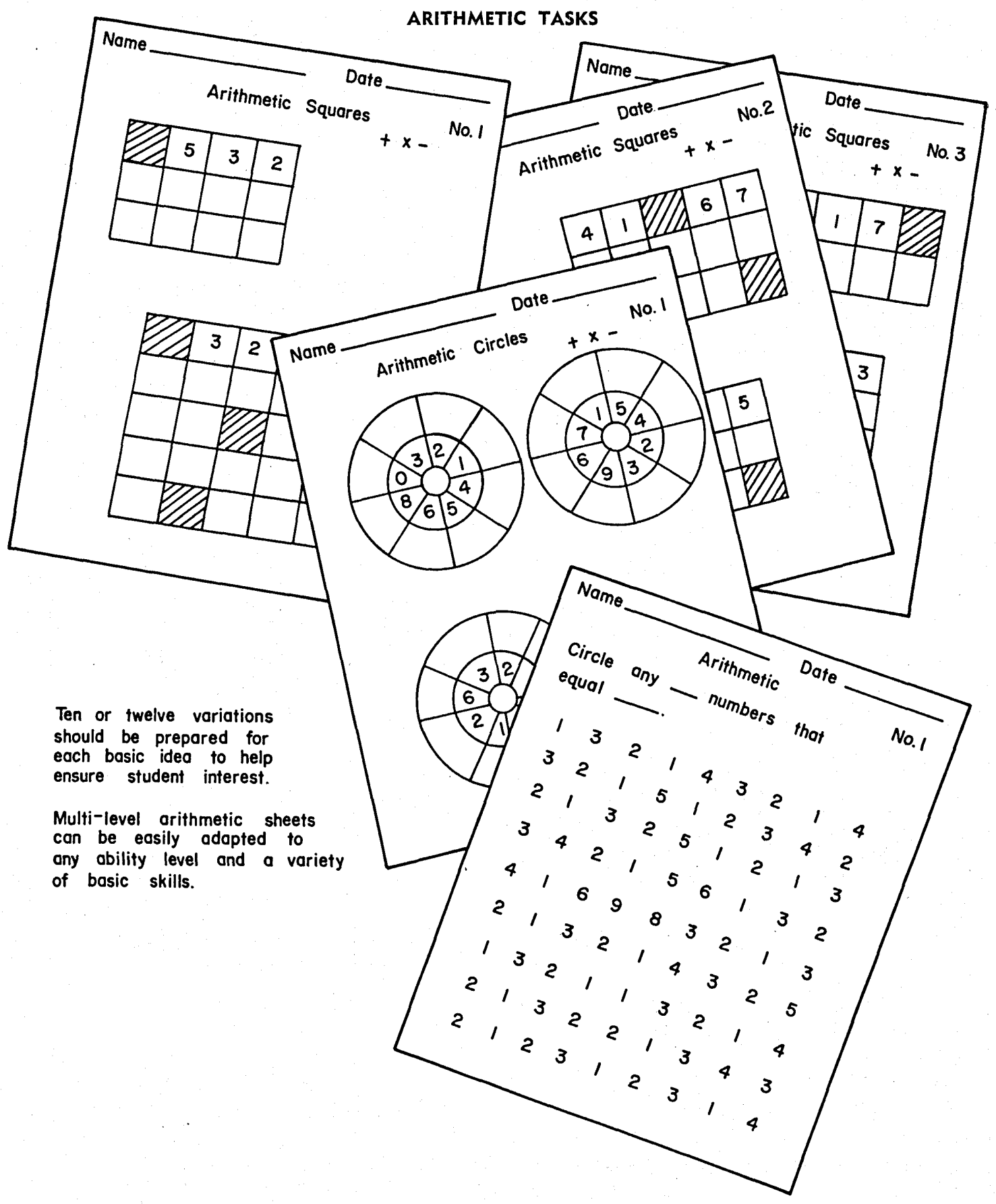


rather than because it falls within any particular grade level curriculum. It may be recalled that the exploratory level falls below the mastery level and hence science experiments are chosen for their multisensory rather than intellectual value. Nevertheless simple, accurate descriptions of all science experiments are given by the teachers to each group. (Figure $\mathrm{X}$ ) Following the introduction of each day's science task the card is filed at the center and is available for students during the interventions.

Art activities are varied and have been organized by the Santa Monica staff to include projects which allow the child self-expression. An attempt is made to keep these tasks simple so that they can be completed within a 25-minute work period. However, the children may

Tasks are selected for their multisensory rather than intellectual value. Each task uses concrete manipulative materials in a situation with a predictable outcome that provides the student with an opportunity to explore his environment.

Many fine commercial materials and ideas are available.
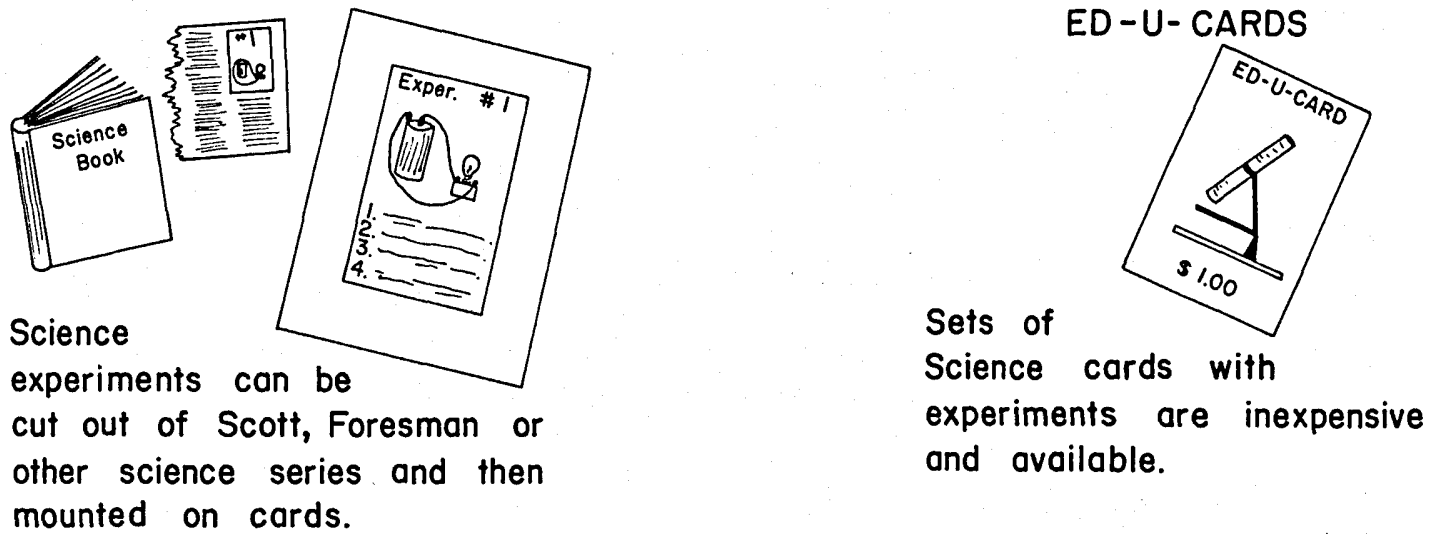

mounted on cards.

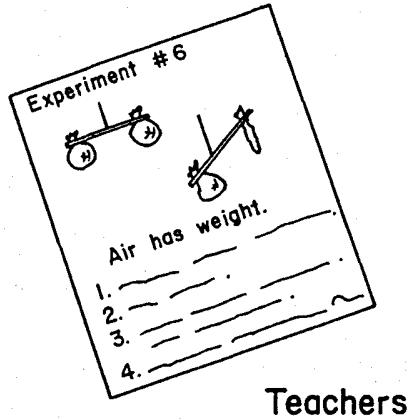

can collect science ideas

from many sources and prepare cards with appropriate science tasks.

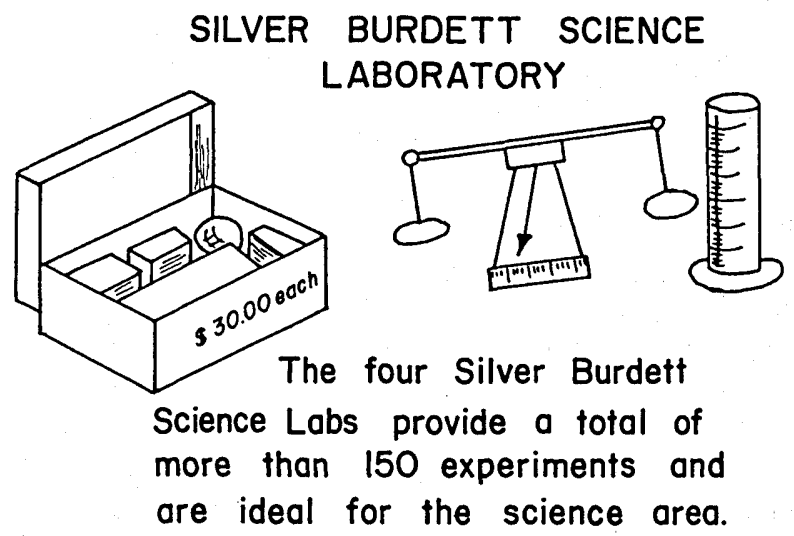

SILVER BURDETT SCIENCE ABORATORY 
continue them over from one day to the next. The art task cards are also filed at the art area for later reference and replication. Ideas from district guides, the Instructor and Grade School Teacher, have been used. (Figure XI)

Communication tasks for building social skills are introduced during the exploratory period and are also filed at the communication area for later usage. Since games entered into by two or more children inevitably involve a winner, those based more on chance rather than skill have proven most successful. Activities

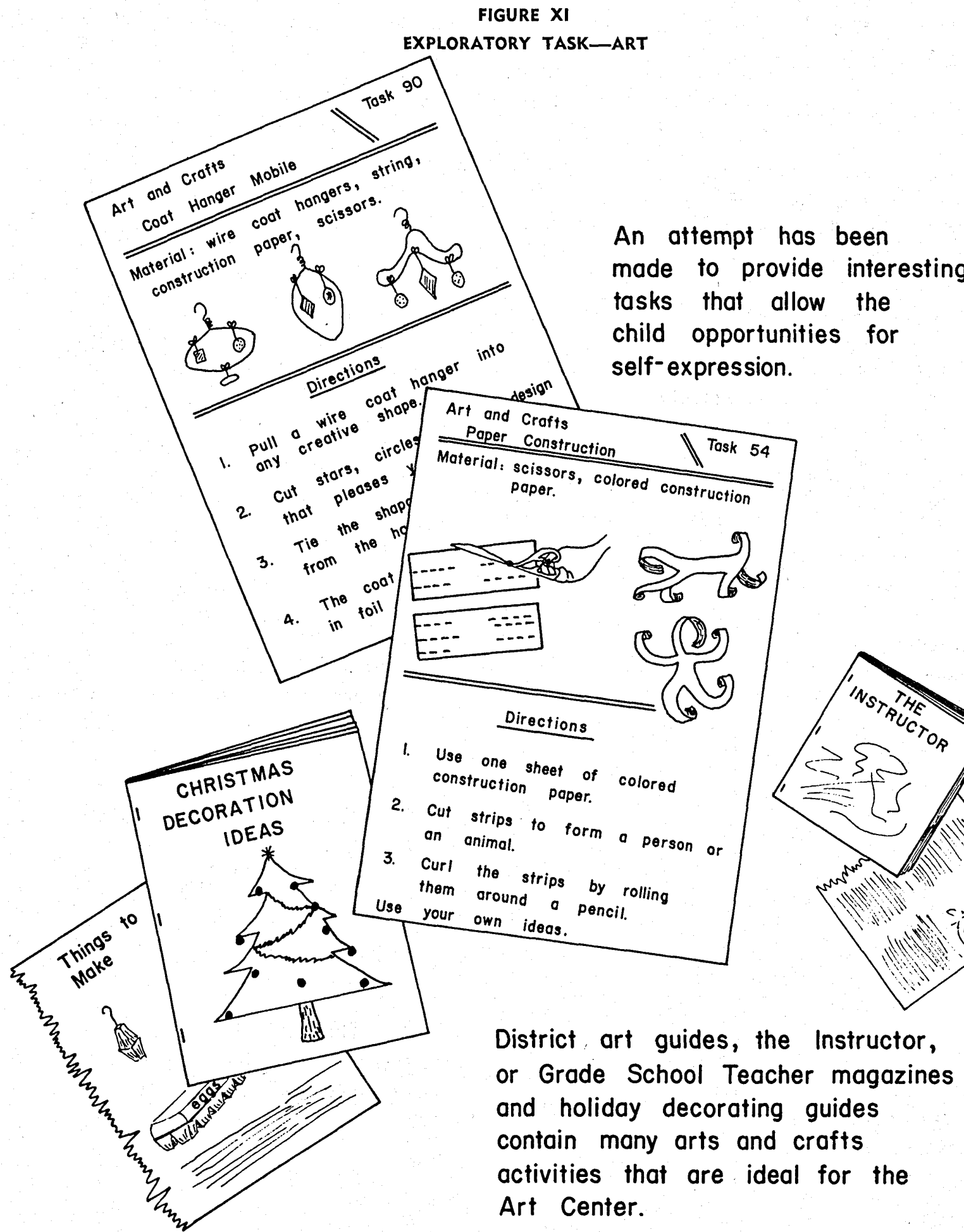


like chinese checkers, chess, battleship, tic-tac-toe, hangman, etc., have also been used successfully. (Figure XII)

The teacher is in command of the classroom and has many resources to manipulate students creatively in a constant effort to insure the success of each student. How- ever, it is still unrealistic to assume that the developmental sequence of educational goals, classroom organization, check mark system, and interventions represent a foolproof formula for success with all educationally handicapped children. The guidelines do, however,

FIGURE XII

EXPLORATORY TASK-COMMUNICATION

Communication tasks are designed to place two or more students in a structured situation with opportunities to build social skills, wait, take turns and share.

Since the games often involve a winner, activities based on chance rather than skill have proven most successful. successful. $x$

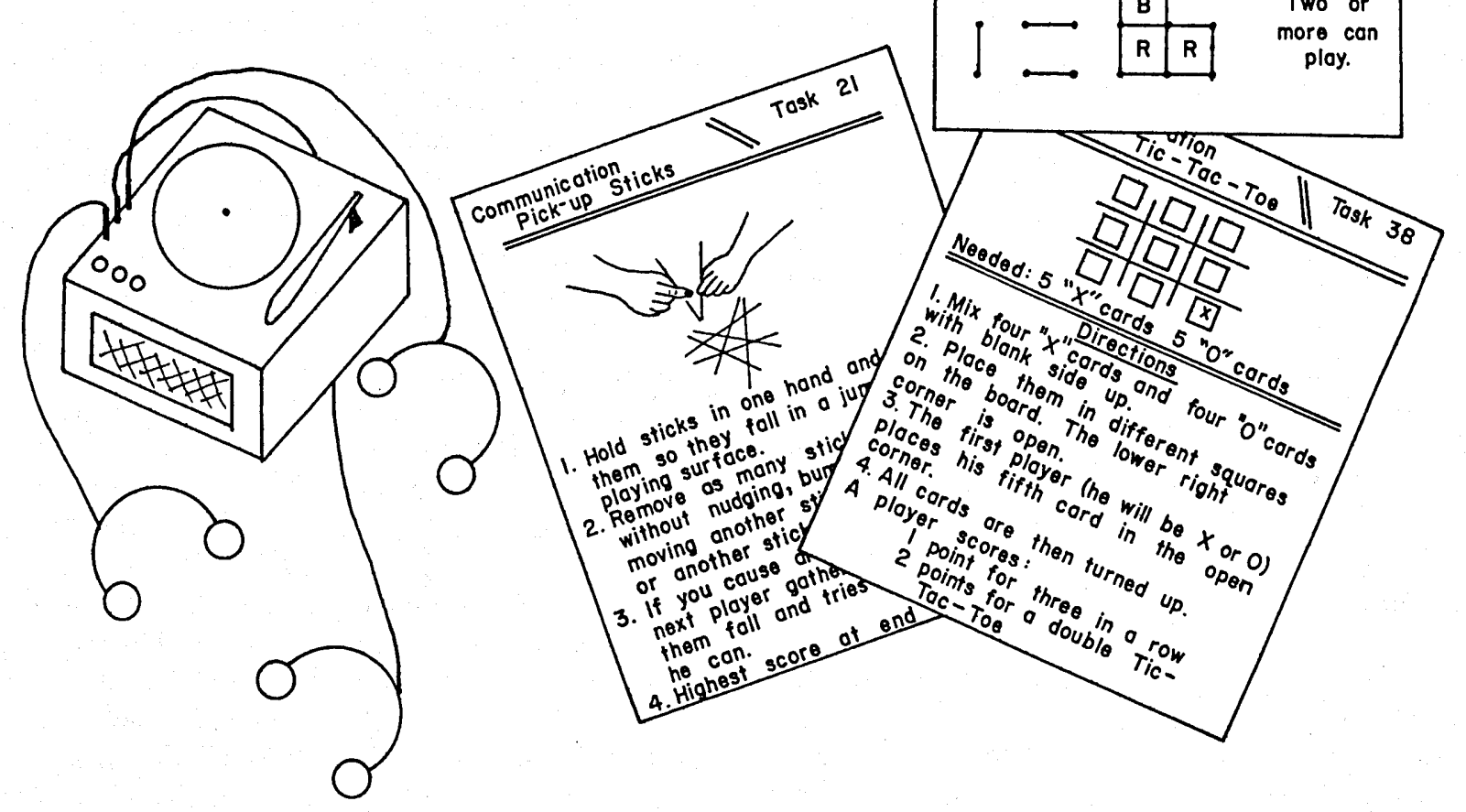

Ideas for Communication Tasks can be obtained from children's paper and pencil game books; adapting simple card games or modifying commercial puzzles and activities. 
offer sound educational, psychological, and developmental principles for training more effective teachers and establishing more adequate classrooms for disturbed children than is often possible through reliance on subjective judgment, intuition, and "cafeteria" approaches.

During the 1966-67 school year the first of two extensive evaluations supported by a U.S. Office of Education Grant \#OEG-4-7-062893-0377, was conducted to determine the effectiveness of the engineered classroom design.

Four elementary schools and one junior high school were selected in the district and one or two project classrooms set up in each school. The junior high school class and one elementary class were not statistically compared but were used for innovative and demonstration purposes during the first year of the project. The junior high school class was evaluated during the 1968-1969 school year when a second class at the same grade level was added.

Six female elementary school teachers were selected from among new teaching applicants in the Santa Monica district for the project. Two additional teachers were selected to conduct the innovative and demonstration classes at the elementary and junior high level.

A two-week training program was conducted in order to acquaint the teachers with the developmental strategy and the engineered classroom design. At the close of the training program each project teacher's name was placed on a slip of paper, the slips shuffled, and then drawn one at a time in order to determine assignment to either an experimental classroom or a control classroom. Experimental teachers were to adhere rigidly to the engineered design, including the giving of check marks every fifteen minutes, while control teachers could use any aspect of the developmental strategy or engineered classroom design they chose except check marks or other token or tangible rewards.

Eight teacher aids without prior teaching experience, were selected for the project, including housewives and graduate students. They were given the same preliminary training as the teachers and then randomly paired with project teachers so that the nine students in both experimental and control classrooms were supervised by both a teacher and an aide.

The children were grouped into six classrooms of nine students each on the basis of IQ, age, and reading and arithmetic levels, in that order of priority. Some attempt was made to place children in classes which would be housed in or near their regular elementary schools, but no child was assigned a group because it was felt that he could profit more from the experimental, or control condition. The class groups were completed before any assignment of teachers or classroom condition was made.

The dependent variable in the project's experimental design included achievement testing three times over the year and daily task attention measurements. Task attention was recorded by two observers present in both experimental and control classrooms who clocked the number of seconds each child's eyes were on an assigned task during five-minute samples taken five times daily. In general, children in the experimental classrooms utilizing the engineered design enjoyed a five to twenty percent task attention advantage over children in the control classrooms not using the check mark system. Experimental classes which abruptly withdrew the design at midyear showed no decrease in task attention-in fact they improved. While reading and spelling gains were not significantly different between experimental and control conditions, gains in arithmetic fundamentals were significantly correlated with presence of the engineered design. During the second federally funded project year 1968-69 it was found that academic emphasis in reading could be increased in the Engineered Classroom, producing statistically significant results.

As part of this second year project three groups of students were compared. Educationally handicapped (EH) students in Engineered Classroom, students identified as educationally handicapped but left in regular classroom, and "normal or average" students in regular classrooms. The EH students in the Engineered Classrooms outdistanced their $\mathrm{EH}$ counterparts in the regular classrooms and approached or exceeded the "normal" students both academically and behaviorally.

Evaluation of the Engineered Classroom design reveals its effectiveness for "launching" children into learning so that they are more susceptible to regular classroom instruction. The evaluation also indicated that a carefully controlled environment with flexible task assignments and a wide variety of rewards-in other words, true individualization of instruction coupled with a guarantee of success-does not promote prolonged dependency on "freeloading" but effectively gets the child ready for more traditional school learning.

\section{BIBLIOGRAPHY}

Hewett, F., Taylor, F., and Artuso, A. The Santa Monica Project: Demonstration and Evaluation of an Engineered Classroom Design for Emotionally Disturbed Children in the Public School, Phase 1: Elementary Level, Final Report. Project No. No. 62839, Demonstration Grant No. OEG-4-7-062893-0377, Office of Education, Bureau of Research, U.S. Department of Health, Education and Welfare, 1967. 
Hewett, F., The Emotionally Disturbed Child in the Classroom: A Developmental Strategy for Educating Children with Maladaptive Behavior, Boston: Allyn and Bacon, Inc., 1968.

Hewett, F., Taylor, F. and Artuso, A., The Engineered Classroom: An innovative Approach to Education of Children with Learning Problems, An unpublished report for Warren J. Aaronson, Director, Title III program, Project Centers Branch, Bureau of Education for the Handicapped, United States Office of Education, 1969.

Quay, Herbert C., and Peterson, Donald D., Behavior Problem Checklist, University of Illinois Children's Research Center, 1967.

Quay, Herbert C., and Werry, J., Deviant Classroom Behavior Frequency Count, University of Illinois Children's Research Center, 1967.

RESOURCE

MATERIALS

By Reuben Altman and Linda Smith ${ }^{1}$

\section{INTERNAL REVENUE SERVICE}

Current educational programs geared to preparing exceptional children and youth for full participation in the work-a-day world demand recognition of accompanying responsibilities and obligations of citizenship. The pervasive nature of Federal Income Tax requirements suggests that instruction in the filing of tax returns be a particularly important inclusion in junior and senior high school curriculum. The Teaching Taxes Program of the Internal Revenue Service provides free materials intended to achieve this end. The program for 1970 consists of three publications and a $32^{\prime \prime} \times 42^{\prime \prime}$ sample tax form enlargment for efficient classroom demonstration. The two student texts, Understanding Taxes and Understanding Taxes-Farm Edition, contain detailed tax procedures, illustrative tax problems, sample tax forms, and supplementary budgetary information. Also available is a teacher's guide offering solutions to the text problems as well as sample questions and instructions for obtaining additional teaching aids.

The Internal Revenue Service requests that inquiries be submitted through the principal in order to consolidate orders from any one school. Materials and/or brochures should be requested from the Teaching Taxes Coordinator of your Internal Revenue District Office.

1. Reuben Altman is Consultant and Linda Smith is Curriculum Specialist, Special Education Instructional Materials Center, University of Texas at Austin.

\section{THE CONTINENTAL PRESS}

The Continental Press publishes a series of Special Education materials and non-reading activities designed specifically for slow learners and the mentally retarded. The series consists of packets containing from 16 to 24 carbon masters for liquid duplicating. Thirty-three individual packets are available providing lessons in reading, writing, and spelling readiness in addition to arithmetic and practical mathematics. The sequentially presented discrimination tasks stress the development of visual perception skills prerequisite to higher cognitive abilities. Inasmuch as materals are reproducible, additional copies can be made available should exercises need to be reworked. A special feature of the Continental Press catalog is exact miniature reductions of the corresponding full size $\left(8 \%^{\prime \prime \prime} \times 11^{\prime \prime}\right)$ carbons in each title. A detail teacher's guide is included free with each packet priced at $\$ 3.50$. Materials and the demonstration catalog may be ordered from: The Continental Press; Elizabethtown, Pennsylvania 17022.

\section{NATIONAL WILDLIFE FEDERATION}

The National Wildlife Federation is a non-profit educational organization disseminating informational materials useful in teaching units in social studies and science bearing on conservation, nature, and plant and animal life. Available publications include Wildlife of Lakes, Streams and Marshes, Birds, Flowers and Trees of America, Learn to Live with Nature and Water. Single copies of most pamphlets may be acquired at no cost with nominal charges made on quantity orders. The Federation offers a membership plan for pre-teenagers featuring Ranger Rick's Nature Magazine, a 48-page publication, illustrated in color and issued ten times each year. Enrollment in Ranger Rick's Nature Club is $\$ 6.00$. An adult membership plan for $\$ 5.00$ provides the conservation magazine, National Wildlife, and other special privileges including book discounts, special travel, library benefits, and a free Art Print of the Year. A brochure listing publications by grade level, available periodicals, an order form, and other information about the Federation may be obtained by contacting: National Wildlife Federation; 1412 Sixteenth Street, N.W.; Washington, D.C. 20036.

\section{READER'S DIGEST SERVICES, INC.}

Reader's Digest Services features Reading Skill Builders and Adult Readers, both of which approximate the nationally known parent magazine in format. The Skill 
Builders present stories previously published in the Reader's Digest which have been adapted to grade levels one through eight and provide a controlled reading level with a high interest appeal. In addition to the pupils books, teaching aids such as Practice Pads, comprehension exercises, and annotated teacher's editions accompany the series. The Adult Readers consists of 12 books designed to provide remedial training for adolescents and adults who are reading at an elementary grade level.

The Young Pegasus Packets were created to enrich basic social studies and language arts in preschool and first grade programs. Each collection of multi-ethnic stories and games includes a teacher's manual. The Reader's Digest Readings, a series of six textbooks, are intended to promote an increase in vocabulary for children and adults learning English as a second language. To receive a catalog of their educational materials along with cost information, write: Reader's Digest Services, Inc.; Educational Division; Pleasantville, New York 10570.

\section{WASHINGTON REPORT}

Determined to help solve the difficulties that state and local governmental units, education facilities, private organizations and individual citizens encounter when trying to learn about federal assistance programs, Congressman William V. Roth and his staff recently compiled a catalog of information about current programs.

The 1969 Listing of Operating Federal Assistance Programs Compiled During the Roth Study, a 1,132 page catalog, is the most comprehensive such listing ever compiled. It contains complete, though concise, information about 1,315 federal assistance programs. In addition to the name of each program the following information is given: (1.) Authorizing Statute: Indicates the authorizing legislation; (2.) Administrator: Names the agency and the specific office which administers the program; (3.) Nature of the Program: Describes objectives and purpose; (4.) Eligibility: Lists those eligible for benefits (state, county, city, group, individual); (5.) Available Assistance: Specifies the types of assistance available (6.) Use Restrictions: Indicates the purposes for which funds can be spent; (7.) Appropriations: Lists current and past appropriations; (8.) Average As- sistance: Shows the average size of a grant or loan; (9.) Assistance Prerequisites: Names the conditions the applicant must meet to qualify for assistance; (10). Postgrant Requirements: Indicates the reporting and evaluation necessary after the grant expires; (11.) Washington Contact: Gives the name, address, and telephone number of the Washington official to contact; (12.) Local Contact: Gives name, address and telephone number of the regional or state official to contact; (13.) Application Deadlines: Gives deadlines for application; (14.) Approval/Disapproval Time: Indicates the average wait between receipt of application and notification; (15.) Related Programs: Lists related programs administered by the same or other agencies.

Obviously not all of the many programs described in the Roth Study will be of interest to the educator, but he will find this catalog a single repository of much important education information. This volume may be obtained free of charge from your congressman.

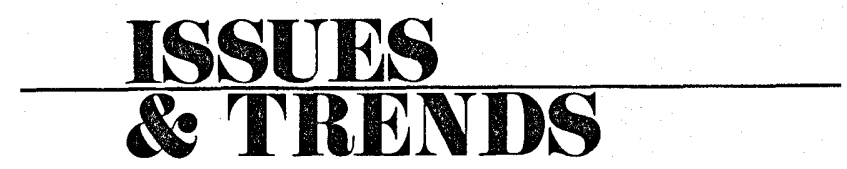

The engineered classroom concept discussed in the lead article of this issue is significant in several aspects. It encourages precision in teaching and allows the student to obtain immediate feedback on his progress. While these aspects in themselves warrant merit the involvement of the researchers in the program is also significant. To carry out such a project a researcher would need to be involved with the teaching personnel and remain very sensitive to the activities conducted in the classroom. Too many studies are done without the researcher having any direct relationship with the school setting. He merely designs the study, causes the intervention to take place, and remains only remotely involved.

If applied research is to make a maximum contribution the most relevant problems should be studied. One way to assure that priority problems are being investigated is for researchers to become more involved in the teaching situation. More emphasis needs to be given to cooperative research involving school districts and universities. Through such an approach possibly university researchers will become more oriented and school districts more interested in research. 